\title{
Visible peritoneal catheter during colonscopy
}

A 54-year-old woman with a past history of IgA nephropathy, chronic renal failure, and hypertension was referred for outpatient colonoscopy to investigate a history of change in bowel habit with intermittent diarrhea. Non-invasive investigations including stool tests had failed to find a cause.

Physical examination revealed hypertension (blood pressure 160/80) but was otherwise normal. The colonoscopy was largely unremarkable; however the image depicts the unusual finding in the proximal transverse colon of a peritoneal dialysis catheter visibly indenting the wall of the colon ( Fig. 1). Perforation of a viscus is a recognised complication of peritoneal dialysis catheters, although in this case the patient was well and the catheter did not appear to be causing irritation to surrounding structures. This image, with its readily apparent transmural visualisation of an extramural catheter, reminds all who perform colonoscopy of just how thin the wall of the proximal colon is (approximately $3 \mathrm{~mm}$ ) and that caution is constantly required to avoid inadvertent perforation.

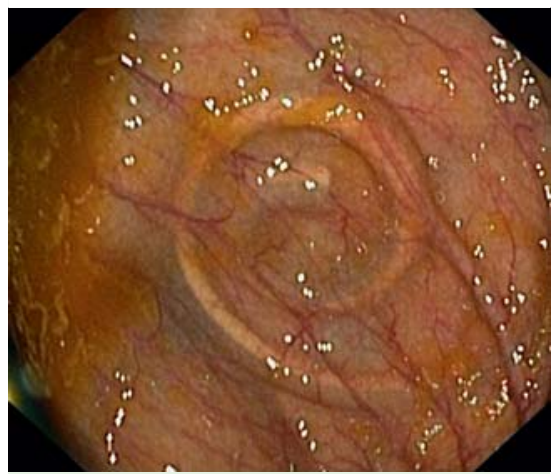

Fig. 1 Peritoneal dialysis cathether embedded in the wall of the proximal transverse colon.
Endoscopy_UCTN_Code_CCL_1AD_2AJ

Competing interests: None

\section{S. E. Mahady, M. Bourke}

Department of Gastroenterology, Westmead Hospital, Wentworthville, New South Wales 2145, Australia

Bibliography

DOI $10.1055 / \mathrm{s}-0030-1256268$

Endoscopy 2011; 43: E175-E175

(c) Georg Thieme Verlag KG Stuttgart · New York . ISSN 0013-726X

Corresponding author

\section{S. E. Mahady MBBS, FRACP}

Department of Gastroenterology

Westmead Hospital

Wentworthville

New South Wales 2145

Australia

Fax: +61-2-98455118

Suzanne.mahady@gmail.com 